Staphylococcus aureus إستعمال مستخلص قشور الرمان في تثبيط نمو وتحسين نوعية صوصج اللحم المصنع محلياً

\begin{tabular}{|c|c|c|c|}
\hline شهرزاد محمد الثديدي & ميعاد غالب باقر & فارس عبد علي العبيدي & علي حسين علي حميد \\
\hline فرع الصحة العامة & فرع الكيمياء & وحدة الامراض المشنركة & وحدة الامراض المشتركة \\
\hline كلية الطب البيطري & كلية طب الكندي & كلية الطب البيطري & كلية الطب البيطري \\
\hline جامعة بغداد & جامعة بغداد & جامعة بغداد & جامعة : \\
\hline
\end{tabular}

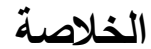

Staphylococcus إستهذف البحث تقييم الاثر التثبيطي لمستخلص قتشور الرمان تجاه بكتريا aureus

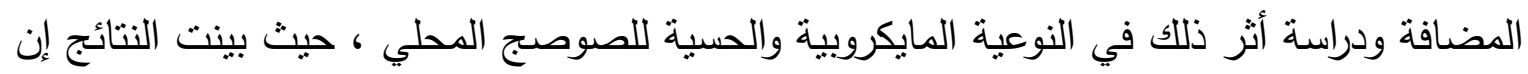
Staph. aureus اضافة 0.22 \% من مستخلص قنثور الرمان قد ساهم في تثيط نمو بكتريا

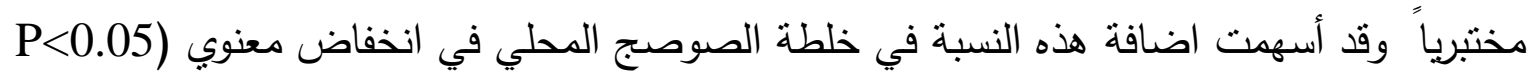
) في اعداد البكتريا الكلية وتثبيط نمو بكتريا Staph. aureus الى الحد الذي لم تعزل فيه ولم تظهر تأثثرات معنوية لاضافة مستخلص فثور الرمان في صفات النكهة والطراوة والعصيرية مما يدل

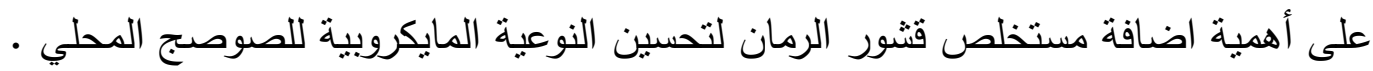




\section{Using Punica 1. Shell Extract As A bacteriostatic For Staphylococcus aureus And Inhancing Locally Processed Sausage}

Ali H. Ali

Zoonosis unit

College of Vet. Med.

Baghdad University
Faris A. Al-Obaidi

Zoonosis unit

College of Vet. Med.

Baghdad University
Meiad G. Baqir

Dept. Of Biochemistry

Al-Kindi Med.

Baghdad University
Shahrazad M. Al-Shadeedi

Dept. of Public Health College of

Vet. Med.

Baghdad University

\section{SUMMARY}

This study was carried out to evaluate Punica L. shell extract as a bacteriostatic for Staphylococcus aureus Invitro, and select the minimal dosage to used as a food additive with species for processing locally sausage and evaluate the microbial and sensory quality. The results obtained revealed that $0.22 \%$ of Punica L. extract was the minimum dose has the effective bacteriostatic for Staph. aureus Invitro and adding this percentage in mixture of locally processed sausage significantly decreased total bacterial count and no growth of Staph. aureus were noticed. No significant differences in the sensory quality of the processed sausage was observed .

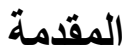

ينتمي الرمان الى العائلة الرمانية (Punicaceae ) وهي عائلة صغيرة تحوي جنساً واحداً

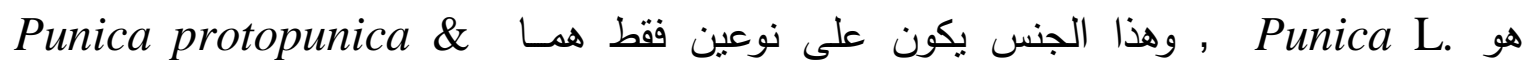

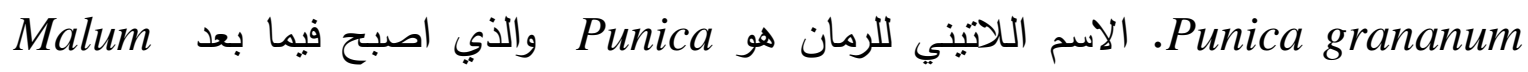
punicum وفي العراق يوجد النوع الاول فقط وهو يحتوي الرمان على مواد كيميائية مختلفة فتحتوي القشور الخارجية للجذع على المادة الفئل الفعالة

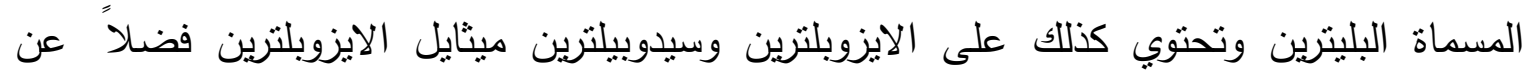

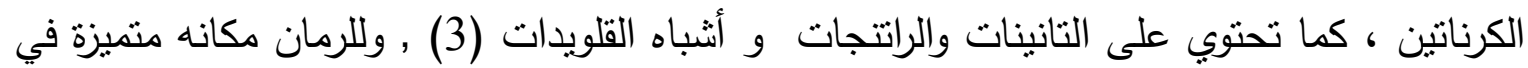

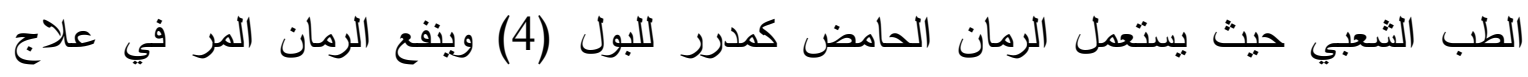

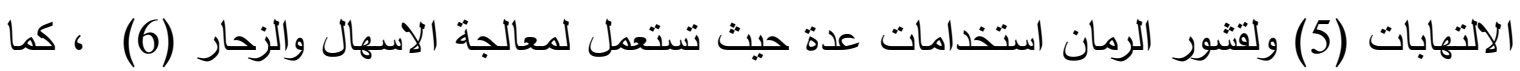

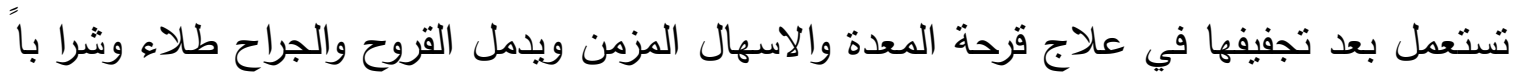
(7) واذا نقعت قنشور الرمان بالماء وشربت في كل صباح اسقطت الدودة الوحيدة (8) , ونظراً

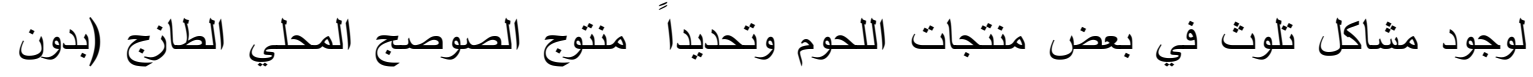

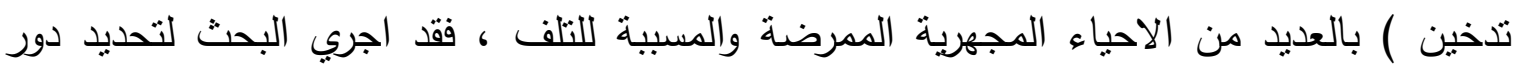


مستخلص قشور الرمان في تثتيط نمو Staph. aureus مختبرياً فضلاً عن أجراء دراسة تطبيقية

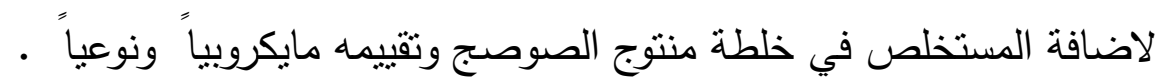

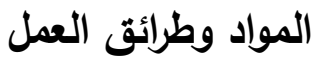

اجري البحث في وحدة الامراض الشتركة / كلية الطب البيطري / جامعة بغداد مستهدفاً تقييم

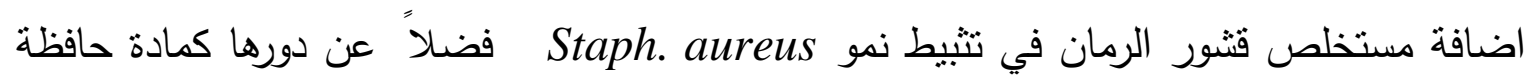

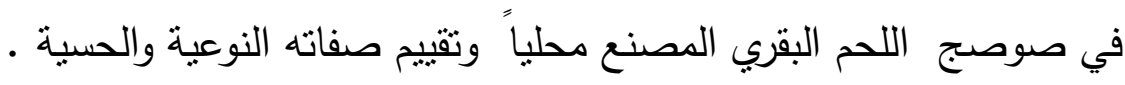
مستخلص قشور الرمان

تم الحصول على المستخلص باستعمال الماء المقطر البارد وكما ذكرته (9) حيث وزنت كمية من مسحوق قثور الرمان المجف (5 غم ) وأضيف لها (300) مل من الماء المقطر ثم مزجت بالتحريك المغناطيسي لمدة 24 ساعة وفي درجة حرارة الغرفة ، ثم فصل المزيج باستخدام جهاز الطرد المركزي وأخذ الراشح وجف باستعمال الفرن الكهربائي بدرجة (50) م لددة 48 ساعة .

\section{Staph. aureus بكتريا}

استعملت عزلة مشخصة من Staph. aureus في وحدة الامراض المشتركة / كلية

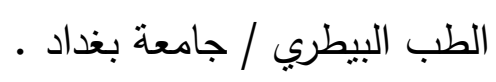

Staph. aureus أختبار الفعالية التثبطية لمستخلص قشور الرمان ضان استعملت طريقة الاقراص الورقية الدذكورة في(10) مع بعض فئل التحويرات ، حيث استعملت

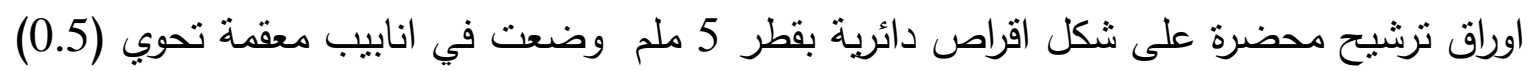

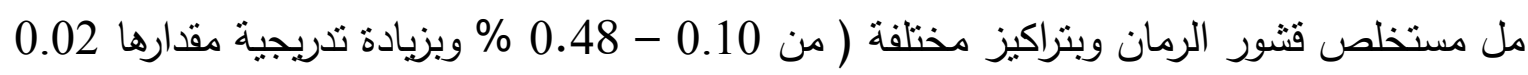

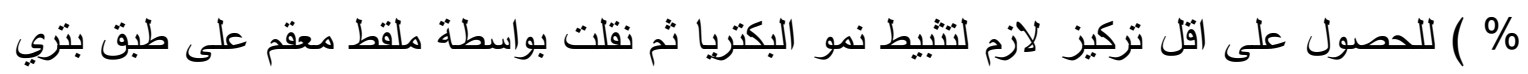

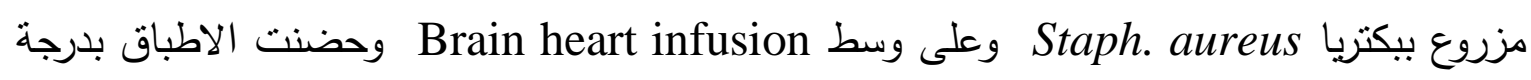

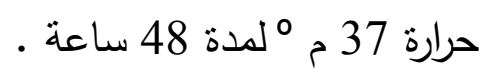

إضافة مستخلص قثور الرمان في منتوج الصوصج مارة

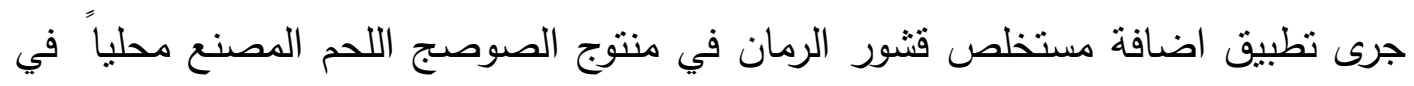

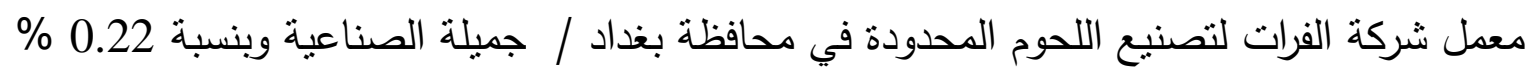
من النسبة الكلية مع اختيار نسبة خلطة بهارات تعادل 0.78 \% من النسبة الكلية وبواقع ثلاثة 
معاملات وهي : الاولى بدون اضافة قثور الرمان والثانية زيادة نسبة البهارات الى 1 \% وبدون اضافة مسخلص قثشور الرمان والثالثة اضافة مستخلص قثشور الرمان بنسبة معينة (تم اختبارها حسب نتائج اختبار الفعالية التثبيطية) ضد بكتريا Staph. aureus عد البكتريا بعد اجراء التخافيف العشرية المطلوبة للعينات (ثلاث عينات من كل معاملة) تم تقدير اعداد

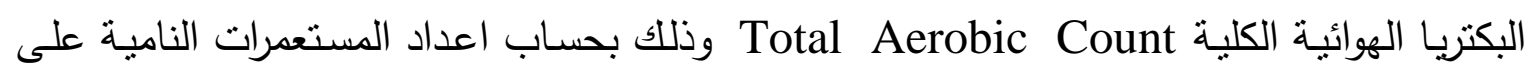
Staphylococcus aureus ونقط Nutrient agar وتعدير اعداد المكورات العنقودية الذهبية وعلى وسط Mannitol Salt Agar وحسب ما ذكر (11 ). وجرى عدّ المستعمرات النامية على

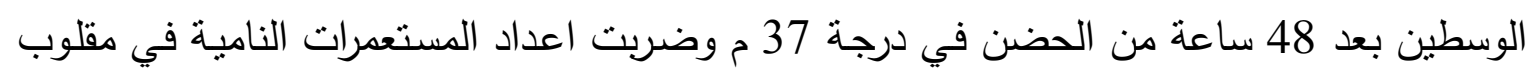

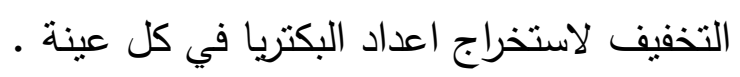

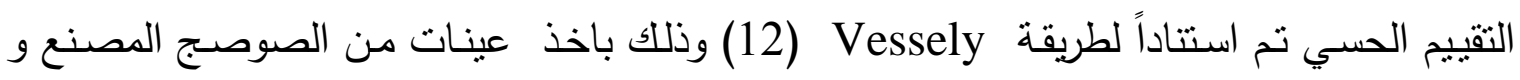

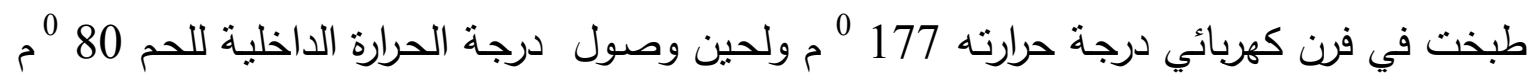

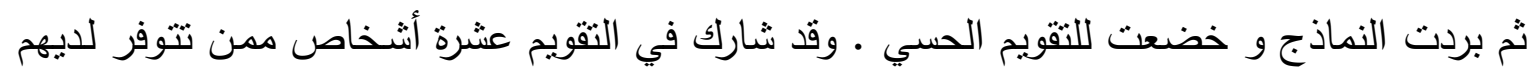

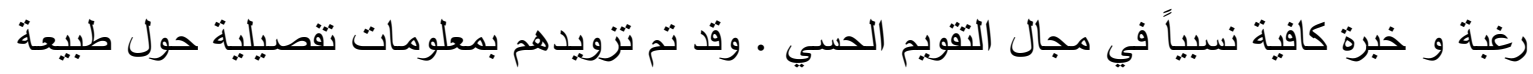

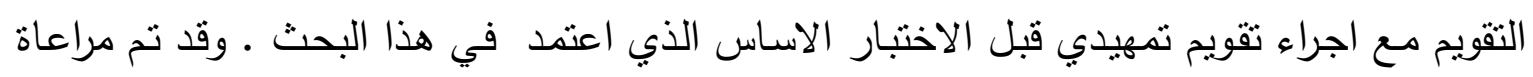

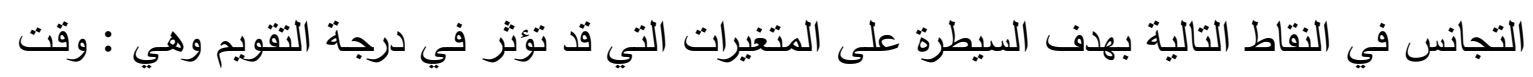

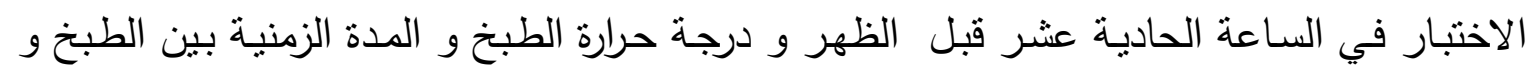

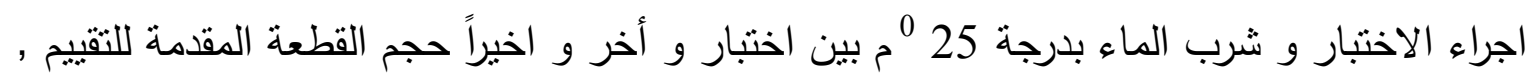

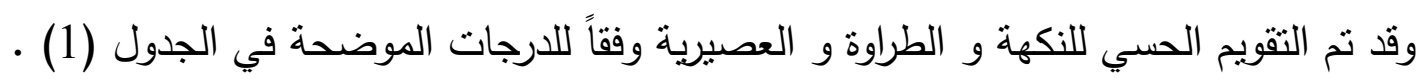


المجلة الطبية البيطرية العراقية، المجلد 31، العدد 2، السنة 2007

الجدول (1): درجات التقييم الحسي المعتمدة

\begin{tabular}{|c|c|c|c|}
\hline العصيرية & الطراوة الط & النكهة & التقدير \\
\hline جاف جداً & طراوة قليلة جداً & نكهة غير مرغوبة جداً & 1 \\
\hline جاف & طراوة قليلة & نكهة غير مرغوبة & 2 \\
\hline متوسط & طراوة متوسطة & نكهة متوسطة & 3 \\
\hline عصبري & طري & نكهة مرغوبة & 4 \\
\hline عصبري جداً & طري جداً & نكهة مرغوبة جداً & 5 \\
\hline
\end{tabular}

. (12) Vessely

التحليل الاحصائي:

تم تحليل البيانـات وفق تجربـة التصـيم العشوائي الكامل ( CRD) , وجرى مقارنـة

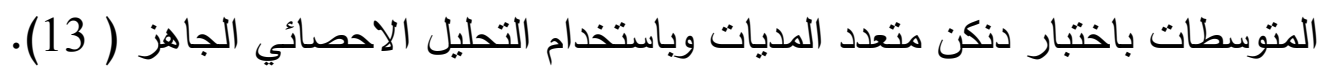

\section{النتائج}

Staph. بينت النتائج ان اقل تركيز لازم من مستخلص قشور الرمان لتنبيط نمو بكتريا aureus

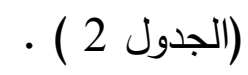

الجدول (2): تاثير تراكيز مختلفة من مستخلص قثور الرمان في قطر منطقة تثبيط نمو بكتريا

\section{- Staph.aureus}

\begin{tabular}{|c|c|c|c|}
\hline قطر منطقة التثبيط & $\begin{array}{c}\text { التركيز } \\
\text { (\%) }\end{array}$ & قطر منطقة التثيط & $\begin{array}{c}\text { التركيز } \\
\text { (\%) }\end{array}$ \\
\hline 4.2 & 0.30 & 2.1 & 0.10 \\
\hline 4.2 & 0.32 & 2.5 & 0.12 \\
\hline 4.5 & 0.34 & 2.7 & 0.14 \\
\hline 4.5 & 0.36 & 2.7 & 0.16 \\
\hline 4.8 & 0.38 & 2.7 & 0.18 \\
\hline 4.2 & 0.40 & 3.2 & 0.20 \\
\hline 4.9 & 0.42 & 3.6 & 0.22 \\
\hline 5.1 & 0.44 & 3.6 & 0.24 \\
\hline 5.5 & 0.46 & 3.7 & 0.26 \\
\hline 5.5 & 0.48 & 3.9 & 0.28 \\
\hline
\end{tabular}




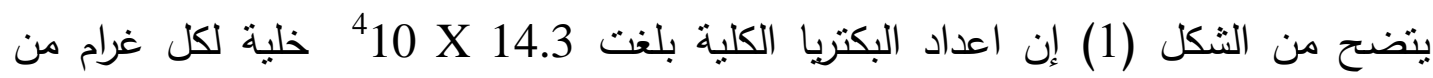

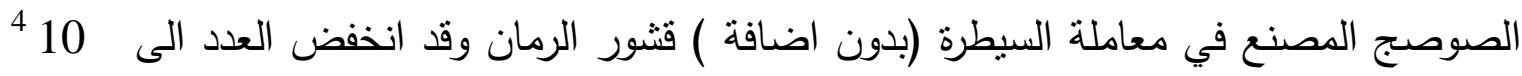

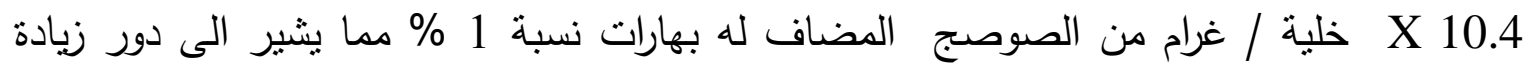
البهارات في خلطه الصوصج في خفض اعداد البكتريا الكلية الا ان اضافة قثور الرمان بنسبة

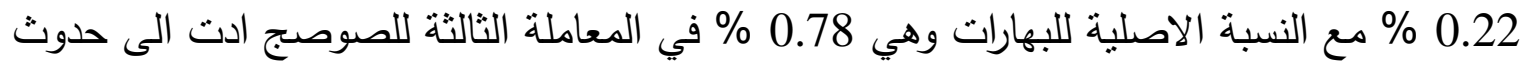

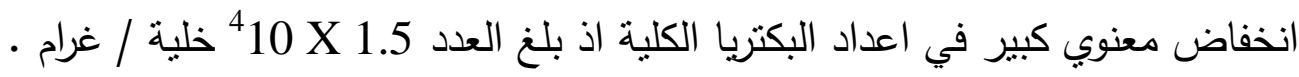

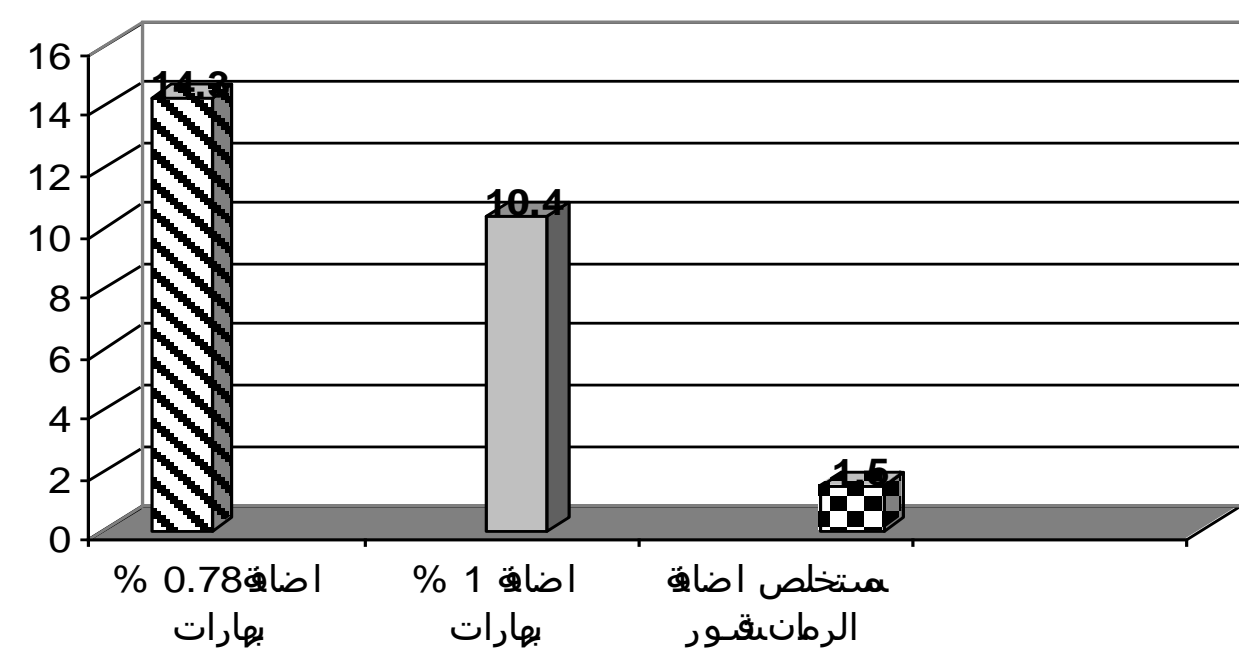

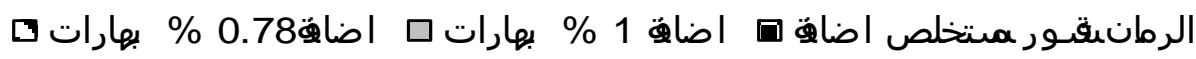

شكل (1) تأثير اضافة مستخلص قشور الرمان في أعداد البكتريا الكلية في منتوج الصوصج (أعداد

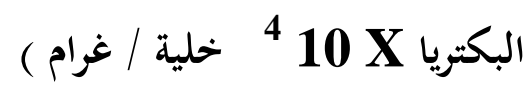

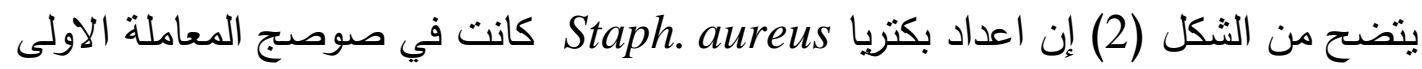
(السيطرة ) 10 3لية / غرام صوصج ولم تنخفض اعداد هذه البكتريا ابداً في صوصـج المعاملة

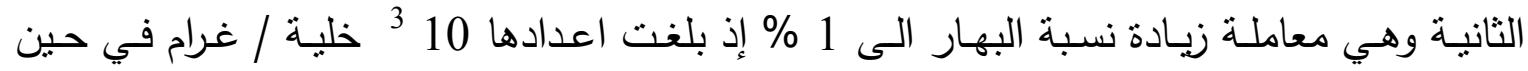

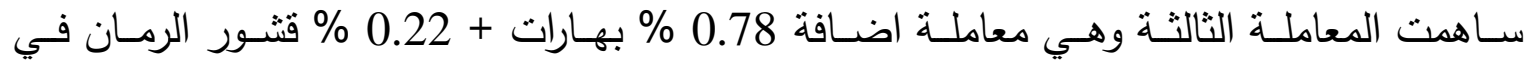

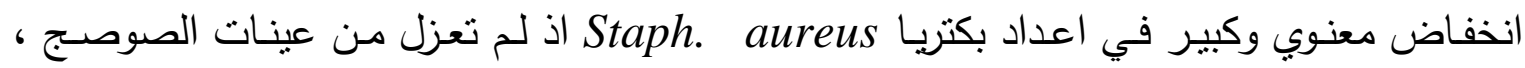
ويتضح من الجدول (3) ان صفات الفحوصات الحسية للصوصج المصنع في المعاملات الثلاثة لم 
تتأثز معنوياً على الرغم من وجود إنخفاض بسيط في صفة النكهة لصوصـج المعاملة الثانية نتيجة زيادة نسبة خلطه البهارات المضافة الى 1 \% مقارنة بالمعاملتين الاولى والثناثة .

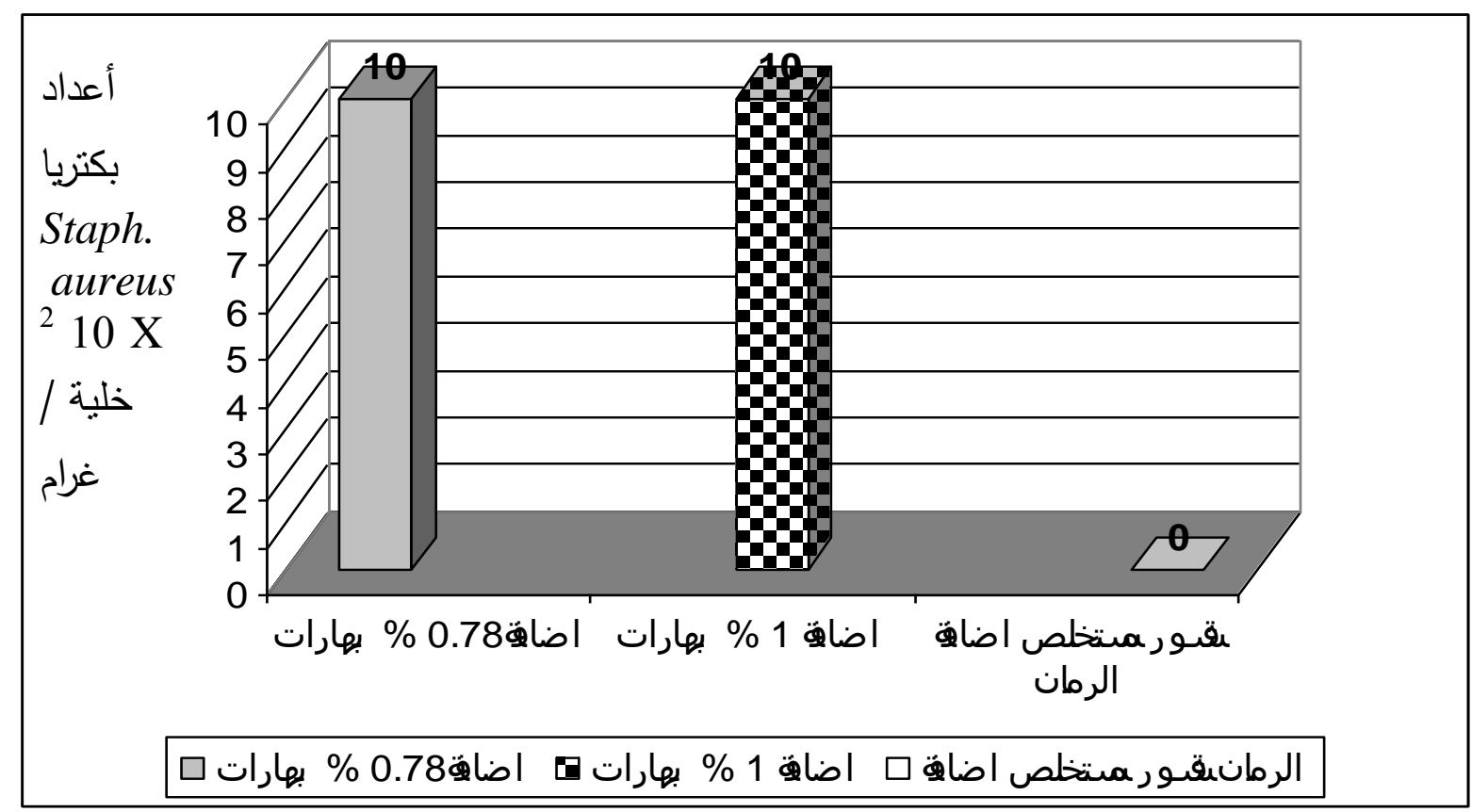

شكل (2) تأثير اضافة مستخلص قشور الرمان في أعداد بكتريا Staph. aureus في منتوج الصوصج (أعداد البكتريا 10 X 2 خلية / غرام)

جدول(3) تاثير اضافة قشور الرمان في التقييم الحسي للصوصج المصنع

\begin{tabular}{|c|c|c|c|}
\hline العصبرية & الطراوة & النكهة & المعامالات \\
\hline 4 & 4 & 4 & 0.78 \% بهارات \\
\hline 4 & 4 & 3 & \% بهارات 1 \\
\hline 4 & 4 & 4 & قشتورالرمان+النسبة \\
\hline N.S. & N.S. & N.S. & المعنوية \\
\hline
\end{tabular}




\section{المناقشة}

تعد المنتجات الغذائية المصنعة من اللحم ذات قيمة غذائية عالية وهي في الوقت نفسه من

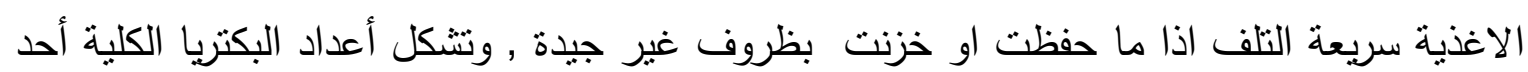

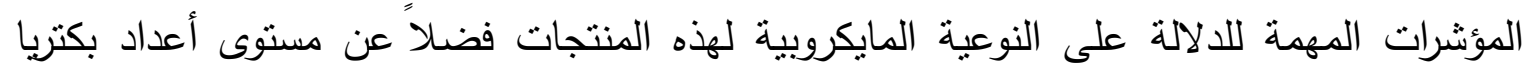

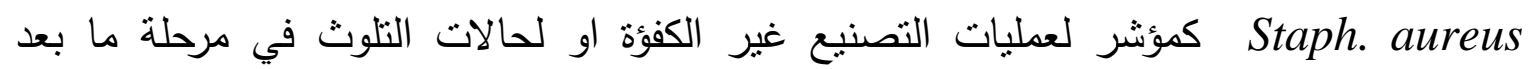
التصنيع جراء التداول السيء وقد سبق وأن اشارت نوصيات جهاز النقييس والسيطرة النوعية لعام 1992 الى ضرورة عدم زيادة اعداد البكتريا الكلية عن 10 كُ لكل غرام وبكتريا Staph. aureus

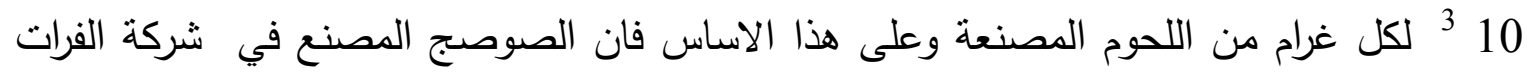

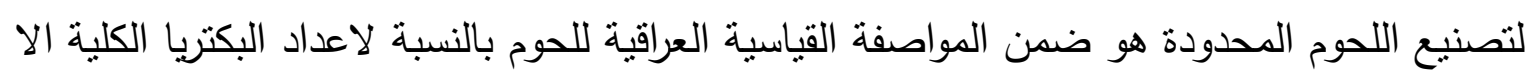

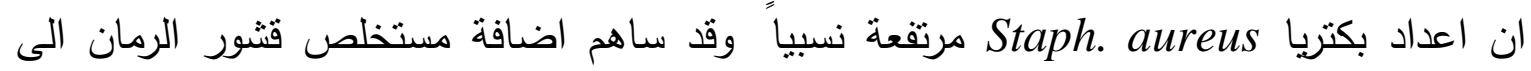

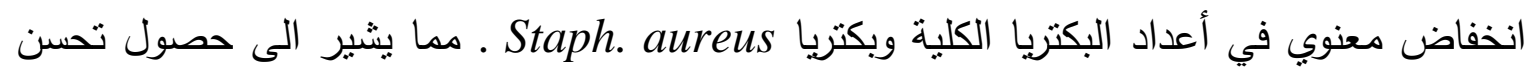

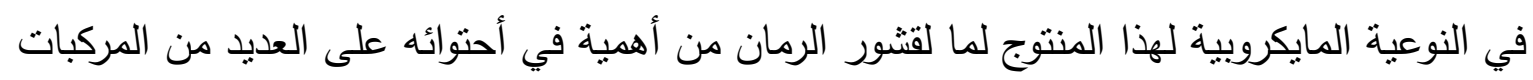

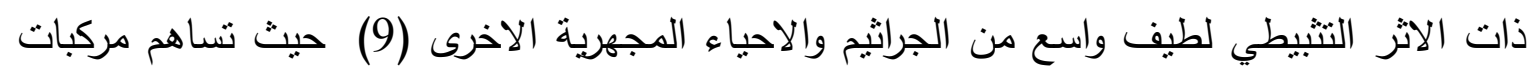

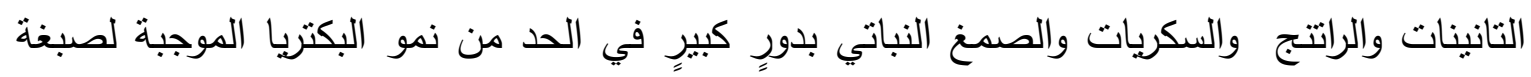
كرام وهذا هو السبب الرئيسي لانخفاض أعداد Staph. aureus في هذا المنتوج عند اضافة قتشور الرمان (14) •

أما بالنسبة للفحوصات الحسية والنوعية فكما انشارت النتائج الى دور زيادة نسبة البهارات

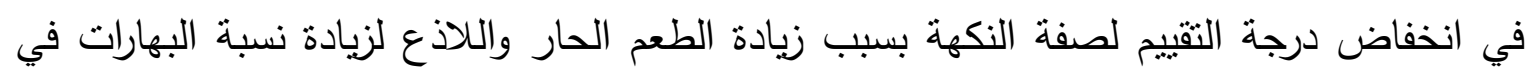
حين لم تظهر اضافة فثور الرمان نغيرات معنوية سواء سلبية او ايجابية في الصفات النوعية

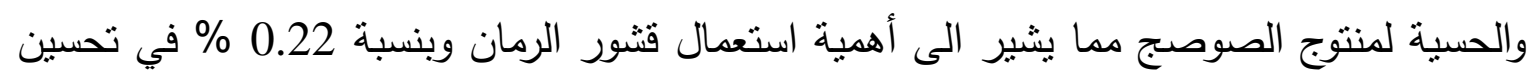
النوعية المايكروبية لمنتوج الصوصج وبالتالي زيادة مدة حفظه وتقليل الخطر على الصحة العامة الصناف

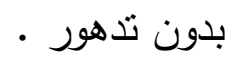

\section{المصادر}

1. Townsend,C.C. and Guest,E. (1980). Flora of Iraq ,Vol.4,Part 1.Baghdad : Ministry of Agriculture and Agrarian Reform.

2. Lawrence,G.H.M.(1951).Taxonomy of Vascular Plants. NewYork: The Macmillan Co.

3. Heinrich, M., Rimpler,H. and AntonioBarrera,N. (1992). Indigenous Phytotherapy of Gastrointestinal Disorders in a Lowland Mixe Community (Oaxaca,Mexico): Enthopharmacologic Evaluation", J. Enthopharmacology . $36: 63-80$. 
4. قبيسي ، حسان (2004). معجم الاعثاب والنباتات الطبية ـ منشورات محمد علي بيضون ـ دار

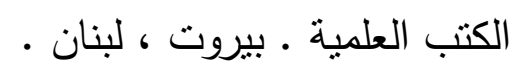

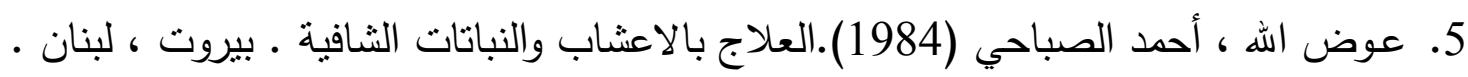

6. Heinrich, M ., Rimpler,H. and Hor,M.( 1995 ). Inhibition of intestinal

chloride secretion by proanthoycyanidins from Guazuma ulmifolia . J. Plant Medica . $61:$ 208-212.

7. القاضي ، عبد اله ، سعد ، شكري ابراهيم ، صالح ، نجم عبد الكريم محمد وخلف اله ، عبد العزيز

محمد (1988) ـ النباتات الطبيه العطرية والسامة في الوطن العربي ، الخرطوم ؛ المنظمة العربية العربية

للتنمية الزراعية .

8. قدامة ، أحمد(1988) ـ قاموس الغذاء والتاداوي بالنباتات ، بيروت : دارالنعاش .

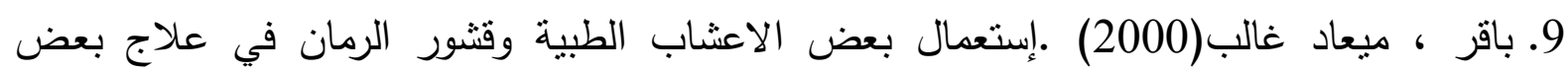

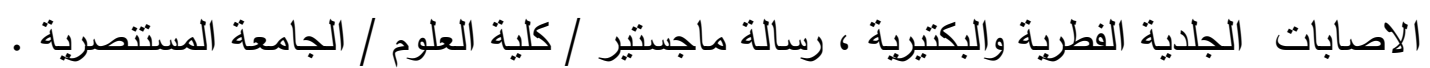

10.Rios, J. L., Recis, M. C. and A. Villar (1988). Screening methods of natural products with antimicrobial activity : A review of the literature . J. Ethopharmacology . $23: 127-149$.

11.Harrigan,W.F. and M.E. McCance .(1979). Labrotary Methods in Food and Dairy Microbiology . Academic Press : London .

12.Vessely , J. A. (1973 ). Fatty acids and steroids affecting flavour and aroma meat from ram cryptorchild and wether lambs .Can. J. Anim. Sci. 53 : 673675.

13.SAS .Institute.(2001 ). SAS/TAT . Guide for Personal Computers . Version 6 Edition SAS Institute Inc, Cary ,N.C.

14.AL-Rawi, A. and H. L. Chakravarty (1988).Medical Plants of Iraq $\quad\left(2^{\text {nd }}\right.$ ed $)$ Baghdad : Ministry of Agriculture and Irrigation . 